\title{
Exploring moderators in the relationship between cognitive adaptability and entrepreneurial \\ intention: Findings from South Africa
}

\author{
Melodi Botha ${ }^{1}$ \& Alex Bignotti ${ }^{1, *}$ \\ 1 Department of Business Management, Faculty of Economic and Management Sciences, University of Pretoria, Lynnwood Road, Pretoria \\ 0002, Republic of South Africa \\ *Correspondence author: Alex Bignotti alex.bignotti@up.ac.za
}

\begin{abstract}
We build on the work of Haynie and Shepherd (2009), who introduced five dimensions of cognitive adaptability in an entrepreneurial context, and Urban (2012a), who explored the relationship of cognitive adaptability with entrepreneurial intention. There is evidence that cognitive adaptability represents a link in the development of intentions and we empirically answer the call to explore moderators of this relationship. We analyse data collected from 602 potential entrepreneurs in South Africa using structural equation modelling. The results indicate that three cognitive adaptability dimensions, namely goal orientation, metacognitive experience, and metacognitive choice, have a positive relationship with entrepreneurial intention. Level of education, age, gender and entrepreneurial type were tested as moderators as they represent personal-level variables related to both cognitive adaptability and entrepreneurial intention in the literature. Level of education moderated the relationship between goal orientation and entrepreneurial intention, as well as between metacognitive experience and entrepreneurial intention. The moderating role of gender affected the positive influence of goal orientation on entrepreneurial intention, which was stronger for females, while the negative influence of monitoring was stronger for males and weaker for females. For the entrepreneurial type moderator, the sample was split between 443 necessity-driven and 159 opportunity-driven potential entrepreneurs. The results revealed that entrepreneurial type moderated the path between metacognitive experience and entrepreneurial intention, which was stronger for necessity than opportunity potential entrepreneurs. The unconventional moderation effects observed in this South African study carry far wider applicability for the development of the theory of cognitive adaptability in an entrepreneurial context.
\end{abstract}

Keywords: Cognitive adaptability; entrepreneurial intention; level of education; gender; age; entrepreneurial type, emerging economy

\section{Introduction}

Entrepreneurship has become the universal mainstay for most countries as a catalyst of economic development (Baumol and Strom 2007; Wennekers et al. 2005). In emerging economies, such as South Africa, entrepreneurship is seen as a solution to low economic growth, unemployment, poverty and social exclusion (Bruton et al. 2008; West et al. 2008). In advanced economies, entrepreneurship is regarded as an important factor contributing to 
economic growth, especially in terms of obtaining new sources of productivity growth and innovation (Naudé 2010, 2011). Therefore, many scholars, both in emerging (e.g Urban 2012a, 2012b) and advanced economies (e.g. Haynie and Shepherd 2009), have focused their efforts on the importance of understanding entrepreneurs and their behaviour in the complex and uncertain environment in which they operate. These learnings have become important for the pedagogy of entrepreneurship and teaching in general as it has been demonstrated that cognitive adaptability can be taught (Haynie and Shepherd 2009).

Baron (2007, p. 167) emphasises that an 'investigation of carefully selected behavioural and cognitive factors can add appreciably to our understanding of the basic processes that underlie new venture creation'. A cognitive perspective within this realm of uncertainty recently ignited a renewed research inquiry into the understanding of the adaptability of entrepreneurs in different business life-cycle stages and circumstances, and more specifically on an individual level (Haynie et al. 2010; Ko 2012; Lanivich 2015; Ling and Chok 2013; Malmström et al. 2015; Townsend et al. 2010; Urban 2012a, 2012b). Flavell (1971, 1976, 1979, 1987), Griffin and Ross (1991) and Schacter (1999) introduced such adaptable cognitions, also collectively known as metacognitive theory and metacognitive awareness (Haynie et al. 2010), which as a process-orientated approach is new to entrepreneurship (Urban 2012a). Drawing on existing theory and empirical work from both cognitive and social psychology on metacognition, Haynie and Shepherd (2009) conceptualize cognitive adaptability as the aggregate of five theoretical metacognitive dimensions: goal orientation, metacognitive knowledge, metacognitive experience, metacognitive choice, and monitoring.

According to Krueger et al. (2000), individuals develop an entrepreneurial intention as a result of a cognitive process whereby they consciously consider the possibility of starting a new business. Fayolle and Liñán (2014, p. 665) suggest future directions for research on entrepreneurial intentions, they call for research to contribute to a better understanding of the entrepreneurial intention decision-making process at the personal level; in particular, considering cognitive scripts in people's minds. This situation will, in turn, allow the design of more effective education initiatives. Limited evidence arose that confirms a relationship between cognitive adaptability and entrepreneurial intention, except for the contribution of Urban (2012a), who found only one cognitive adaptability dimension that supported this relationship. Partial support for cognitive adaptability as a predictor of entrepreneurial intention in the studies by Urban (2012a, 2012b) may have been due to the omission of moderator variables, and the author in question suggests that moderator variables be explored in the cognitive adaptabilityentrepreneurial intention relationship. Based on the theory of planned behaviour and the behavioural aspects of cognitive adaptability we advance the existence of a moderated relationship between cognitive adaptability and 
entrepreneurial intention. Level of education (Khezrlou 2012; Turker and Sonmez Selçuk 2009), age (Khezrlou 2012; Levesque and Minniti 2006) and gender (Schwarz et al. 2009; Sheorey and Mokhtari 2001) emerged in the literature review as some of the main personal-level variables related to both cognitive dimensions and entrepreneurial intention, making them suitable moderators to be investigated. Furthermore, Ko (2012) and Urban (2012a) suggest that opportunity-driven rather than necessity-driven individuals will have higher-order cognitive processes. Therefore, we also investigate the role of the type of entrepreneur, namely, necessity entrepreneurs (Hechavarria and Reynolds 2009; Williams 2009) or opportunity entrepreneurs (Block and Sandner 2009; Hechavarria and Reynolds 2009; Williams 2009), as a potential moderator. Previous studies have found that these types of entrepreneurs have different motivations and intentions regarding entrepreneurship (Acs et al. 2008; Acs and Varga 2005). However, in the context of entrepreneurship there seem to be no studies on cognitive adaptability and the above moderators.

We examine the above relationships in a South African context. In a recent article, George, Corbishley et al. (2016) point out that Africa represents a unique and promising research context for strategy, entrepreneurship and marketing as core disciplines. Along the same line, Bruton et al. (2008) have criticized the almost exclusive reliance on advanced economies as research domains in developing entrepreneurship theory and advocate the use of novel research contexts, especially emerging economies. In shifting the focus to emerging economies, however, these authors urge scholars not to treat them as a uniform research domain, as they differ from developed economies and from one another in many respects (Bruton et al. 2008, p. 7). Based on the widespread view that entrepreneurs and their entrepreneurial ventures are the panacea to all economic problems, countless entrepreneurial interventions, enablers and even concentrated policy restructuring have been implemented in South Africa since 1994 (Naudé, 2010, 2011). Still, economic growth remains low (0.5\% in 2015-2016), unemployment rates have risen (26.7\% in 2016) and an alarmingly low Total Entrepreneurial Activity (TEA) rate of $9.2 \%$ persists (Herrington and Kew 2016). It is concerning to note that entrepreneurial intention is very low in South Africa. Understanding the mechanisms that foster entrepreneurial intention over and above the unsuccessful solutions already implemented is therefore extremely valuable. In emerging economies like South Africa, it is important to focus on understanding the cognitive adaptability of entrepreneurs and how it can enhance entrepreneurial intention. Other developing countries such as Tunisia, India, Puerto Rico and Poland share similarly low entrepreneurial activity (TEA rate ranging between 8.5 and 10.8\%, Herrington and Kew 2016). One potential route for increasing levels of entrepreneurial intention may be focusing on cognitive adaptability; this possibility underlies the study conducted in this paper. 
The first contribution of this paper is therefore the investigation of more complex relationships between cognitive adaptability and entrepreneurial intention, which have received scarce research attention. We conduct an exploratory investigation of the moderators of the relationship between the five dimensions of cognitive adaptability and entrepreneurial intention. We answer the call from Urban (2012a) to test the moderating role of certain personal-level variables by using structural equation modelling. The second contribution is the unveiling of novel insights into the relationship between cognitive adaptability and entrepreneurial intention garnered from a research context different from that in which these constructs originated (George, Corbishley et al. 2016; Zoogah et al. 2015). Mainstream scholars in entrepreneurship research, with reference to cognition, have conducted their investigations from an advanced economy perspective, with a paucity of scientific evidence from emerging economies (Acs et al. 2008). The importance of this study lies both in investigating an under-researched relationship and in the potential to revisit existing theory from the perspective of a novel context of investigation. This research has implications for other emerging economies with similar entrepreneurial activity levels but also carries far wider applicability for the development of the theory of cognitive adaptability in an entrepreneurial context. The third contribution is that the findings may assist policy makers and educators to pay attention to cognitive adaptability and its complex relationship with entrepreneurial intention in efforts to spur entrepreneurship and improve pedagogical interventions.

The paper commences with the theoretical foundation and hypothesis formulation focusing on cognitive adaptability theory and with specific reference to metacognition within an entrepreneurial context. Firstly, metacognitive theory and cognitive adaptability are discussed; thereafter, the five dimensions of cognitive adaptability are explored. A theoretical model is introduced to explain the relationship between cognitive adaptability and entrepreneurial intention, whereby the four moderators investigated in this paper are explained. The method, measures and analytical procedures employed are described and the results are presented. The paper is concluded with the discussion and concluding remarks, as well as limitations revealed and recommendations made regarding avenues for future research.

\section{Theoretical foundation}

\section{Metacognitive theory and cognitive adaptability}

Metacognition incorporates self-regulation and advances this construct to describe the process through which regulation influences the development and generation of new sense making structures as a function of the changing environment (Flavell 1979). A metacognitively aware entrepreneur will recognise a fact and engage in a process 
to identify alternative actions that maximises the likelihood of achieving goals (Haynie and Shepherd 2009; Urban 2012a). Metacognition describes a higher order cognitive process that serves to organise what individuals know about themselves, tasks, situations and the environment in order to promote effective and adaptable cognitive functioning amidst feedback from complex and dynamic environments (Flavell 1976). Metacognition is defined by Akbaria et al. (2014) as the individual's advanced thinking skills to solve problems effectively, also to align thinking and the ability to adapt action and behaviour to environmental complexities and changes. Metacognition is also reflected on by Frith (2012) as a regulated process where cognitive processes are 'monitored and controlled' or occur as a course of 'thinking about thinking'. Cognitive adaptability as a core construct is grounded in metacognitive theory. A clear understanding of metacognition should be displayed prior to the derivation of cognitive adaptability. One can describe the origins of cognitive adaptability as the result of the conjoint effect of the context in which the individual functions and the motivations of that individual through which the context is interpreted (Haynie and Shepherd 2009). It has been suggested that cognitive adaptability enabled by metacognition is an important cognitive process in the entrepreneurial context (Flavell 1979; Haynie and Shepherd 2009).

The above view allows for the depiction and position of cognitive adaptability as the focus of this paper. Haynie et al. (2012) also investigated the ability of individuals without prior entrepreneurial knowledge to effectively adapt decision policies in response to feedback while they perform an entrepreneurial task. Their findings propose insights into the interplay among knowledge, learning, and cognition that are generalizable to activities and actions central to the entrepreneurial process. The five dimensions of cognitive adaptability are captured in a 36-item Measure of Adaptive Cognition (also known as the MAC model) which was developed and tested by Haynie and Shepherd (2009). It was found to have good psychometric properties, as evidenced by its five-factor structure and its validity. The MAC model was further tested and developed by Haynie et al. (2010, 2012), and Urban (2012a, 2012b) applied the five dimensions of the MAC model to predict entrepreneurial intention. Most of the findings on the MAC model from previous studies (Haynie and Shepherd 2009; Haynie et al. 2010, 2012) were conducted in advanced economies in the Northern Hemisphere with the exception of the study by Urban (2012a, 2012b), which was conducted in South Africa. Most of the entrepreneurs in Sub-Saharan Africa are known as necessity-driven entrepreneurs compared to the opportunity-driven entrepreneurs in the Northern Hemisphere (Kelley et al. 2016). The difference between these two entrepreneurial types is discussed in later sections. 


\section{The five dimensions of cognitive adaptability in an entrepreneurial context}

In their study, Haynie and Shepherd (2009) developed a priori five dimensions of cognitive adaptability and employed CFA to validate them. The findings revealed that the five dimensions are significantly correlated $(p<$ $.05)$, and those correlations are positive indicating that these five dimensions work together to capture general cognitive adaptability (Haynie and Shepherd 2009, p. 704).

Goal orientation is directed towards the ability to achieve certain outcomes. The goals that entrepreneurs pursue are interpreted as a function or consequence of the environment in which those goals originate (Urban 2012a). Individuals perceive, and subsequently assign meaning to, the characteristics of the environment in the context of their own goal orientation (Haynie and Shepherd 2009). Entrepreneurs make use of metacognitive awareness to elaborate the contextual information they gather from the environment and subsequently form intentions. Hence, the goal orientation dimension of metacognition affects the entrepreneur's interaction with the environment and how this interaction leads to the formation of intentions (Urban 2012b). Goal orientation serves to engage the metacognitive resources of metacognitive knowledge and metacognitive experience (Haynie and Shepherd 2009; Urban 2012b).

According to Bryant (2006), metacognitive knowledge can assist entrepreneurs to allocate their resources more effectively, especially in an uncertain dynamic work environment (Haynie and Shepherd 2009). Baron and Ward (2004) advance this thinking by the inclusion of information absorption from the environment and the effective translation into valid knowledge, with endorsed reflection on the entrepreneurial process. Importantly, a parallel may be drawn between knowledge of cognition and entrepreneurial cognition (Bryant 2006; Mitchell et al. 2000). According to Liñán et al. (2011), there has been a recent emergence of a 'subjectivist theory of entrepreneurship', where individuals, their knowledge, resources and skills, and the processes of discovery and creativity are at the heart of entrepreneurship (Kor et al. 2007). More specifically, according to this subjectivist view, the entrepreneur's personal knowledge about the institutional environment surrounding the start-up decision influences the formation of entrepreneurial intention (Lüthje and Franke 2003; Urban 2012a). Additionally, metacognitive knowledge enhances the cognitive capacity to learn from changes in the environment and effectively adapt in essence to uncertainty within.

Metacognitive experiences are conscious cognitive or affective experiences that accompany and pertain to any intellectual enterprise (Flavell 1979). Haynie and Shepherd (2009) include the following items in this dimension: thinking about what really needs to be accomplished before starting with a task; using different strategies depending on the situation; organising time and information to best accomplish goals; consciously 
focusing attention on important information; relying on intuition to determine the most effective strategy to use; and depending on intuition to help formulate strategies. Metacognitive experiences occur if entrepreneurs perceive that they are not successful in achieving a task (Haynie and Shepherd 2009).

Metacognitive choice is the extent to which the individual engages in the active process of selecting from multiple decision frameworks the one that best interprets, plans, and implements a response for the purpose of 'managing' a changing environment (Haynie and Shepherd 2009).

Schmidt and Ford (2003) articulate that monitoring includes processes such as identification of the task, to check and evaluate one's progress, and to predict the outcomes of the progress. In regard to this latter dimension of cognitive adaptability, Baron (2007) states that highly successful entrepreneurs exhibit higher levels of monitoring than less successful entrepreneurs, as a self-regulatory mechanism to help them assess, regulate and improve their performance. Monitoring also contributes an increased awareness of one's own cognitive strengths and limitations (Kanfer 1990), and may aid entrepreneurs to effectively regulate their affective reactions, maximising the benefits of positive affect while minimising its potential costs. In an entrepreneurial context, monitoring assists entrepreneurs to make more informed decisions, by considering what control strategies to use to progress in their business, which should result in increased business performance.

\section{The relationship between cognitive adaptability and entrepreneurial intention}

Entrepreneurial intention is 'a self-acknowledged conviction by a person that they intend to set up a new business venture and consciously plans to do so at some point in the future.' (Thompson 2009, p. 676)

Scholars all over the world are identifying, developing and measuring variables that motivate and drive people to start their own business. Liñán et al. (2011, p. 196) acknowledge, 'there is a lack of agreement on the variables that determine the individual's decision to start a venture.' Cognitive approaches have attracted considerable interest (Baron 2007; Krueger 2003); particularly, much attention has been paid to entrepreneurial intention (Liñán and Fayolle 2015). Based on the theory of planned behaviour, process-based models of intention (Ajzen 1991; Shapero and Sokol 1982) have been widely used by scholars (Liñán et al. 2011; Schwarz et al. 2009; Thompson 2009; Turker and Sonmez Selçuk 2009).

The start-up phase of the entrepreneurial process involves the intention to form the venture, based on the recognition of a concrete opportunity. Some authors conducted research on the relationship between 
entrepreneurial intention and learning constructs, which are grounded in cognition, as proposed by Bandura's (1986) Social Cognitive Theory . Piperopoulos and Dimov (2015), for instance, measured the role of theoretical learning interventions versus practical ones in correlating self-efficacy with entrepreneurial intention. They concluded that practical learning interventions significantly enhance entrepreneurial intention. Hence, when practical learning is employed it leads to a positive effect on entrepreneurial intention and higher knowledge assimilation. Saeed et al. (2015) provide evidence on the noteworthy role educational support plays in augmenting self-efficacy and likewise entrepreneurial intention. They also posit that self-realisation, recognition and role are expected to positively correlate with entrepreneurial intention. In addition, there is ample evidence on the role played by cognition in opportunity recognition (George, Parida et al. 2016). Urban (2012b) postulates that individuals with entrepreneurial intention apply some degree of conscious consideration to the possibility of starting a new business, where these intentions are the result of metacognitions. The question arises whether a high level of cognitive adaptability could predict entrepreneurial intention, in terms of motivation to start a new venture.

As stated in the introduction, South Africa is characterized by low levels of entrepreneurial intention, and institutional efforts to promote entrepreneurship have not reaped the intended results. Therefore, the study of alternative mechanisms to foster entrepreneurial intention is relevant to South Africa. Due to the situation in South Africa it becomes important to explore the relationship between cognitive adaptability and entrepreneurial intention, since metacognition is not represented as a dispositional trait but rather as a dynamic, learned response (Urban 2012a) that can be enhanced through experience and training (Haynie et al. 2010). Given that theoretical contributions may come from the study of 'problem domains' (Corley and Gioia 2011) and from the study of the applicability of theories or relationships originated in one context to a novel context (Zoogah et al. 2015), the investigation of the relationship between cognitive adaptability and entrepreneurial intention in a South African context has the potential to provide insights of a universal value for entrepreneurship scholarly research.

In a study by Urban (2012a) the cognitive adaptability dimension of metacognitive knowledge was the only significant predictor of entrepreneurial intention. His sample, however, included only individuals positioned on a tertiary educational level, who have already gained an awareness and more in-depth knowledge of entrepreneurship. No other studies, to the best of our knowledge, have examined the relationship between cognitive adaptability and entrepreneurial intention. Based on this limited evidence on the positive relationship between cognitive adaptability and entrepreneurial intention, it is hypothesised that: 
H1: There is a positive relationship between each of the five dimensions of cognitive adaptability and entrepreneurial intention.

\section{Theoretical model}

Due to the limited number of studies focusing on the relationship between cognitive adaptability and entrepreneurial intention, we propose a conceptual model, illustrated in Figure 1. According to this theoretical model, the relationship between the five dimensions of cognitive adaptability as independent variables and entrepreneurial intention as dependent variable will be tested. The level of education, age, gender and entrepreneurial type are added as moderators between the independent variables and the dependent variable and are discussed below.

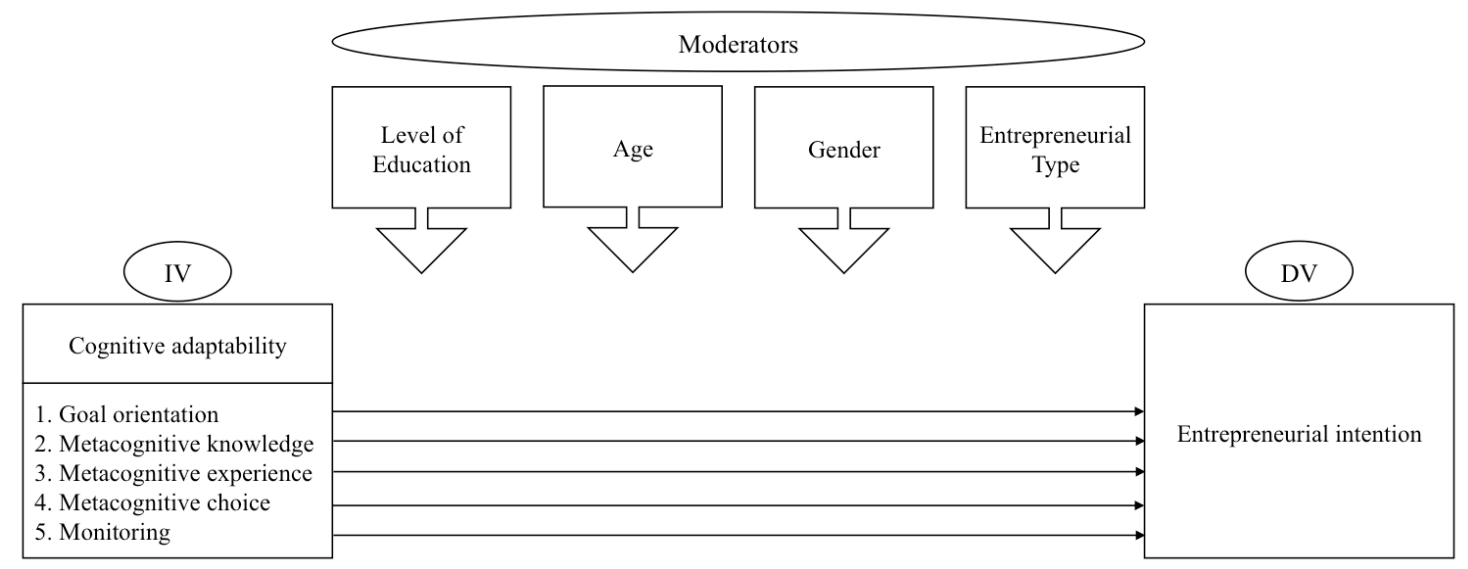

Fig 1 Conceptual model of the relationship between the five dimensions of cognitive adaptability and entrepreneurial intention

There is a proliferation of studies investigating the variables influencing entrepreneurial intention. Among the personal-level variables affecting intentions are some demographic variables, such as gender, age, or labour experience, exerting a significant influence (Levesque and Minniti 2006; Liñán et al. 2011; Minniti and Nardone 2007; Schwarz et al. 2009). For instance, in a study by Wang and Wong (2004), three background factors, namely: gender, family experience with business and educational level, were found to affect entrepreneurial interests. The rest of the literature section will focus on the moderators introduced in Figure 1. While not representing an exhaustive list of moderators, they emerged in the literature review as some of the main personallevel variables related with both cognitive dimensions and entrepreneurial intention. 


\section{Level of education as a moderator}

A number of studies have empirically observed the association between individuals' level of formal education and entrepreneurship (for example: Galloway and Brown 2002; Garavan and O'Cinneide 1994; Hills 1988; Kolvereid and Moen 1997). There is empirical evidence, for instance, that individuals with more years of formal education are more likely to become self-employed and have a higher probability of success than those with fewer years of education (Robinson and Sexton 1994). At the level of entrepreneurial intention, more specifically, Turker and Sonmez Selçuk (2009) observe that the acquisition of an adequate level of education may enhance a person's entrepreneurial intention. Conversely, lower levels of education are typically associated with a lower probability to engage in entrepreneurial activities (Herrington and Kew 2016).

In contrast, Wang and Wong (2004) found a negative relationship between high levels of education and entrepreneurial intention. They argue that education seems to play a deterrent role to entrepreneurship, as senior university students are less interested in start-ups and the longer time spent on campus does not transform to higher interest, even though their business knowledge may increase (Wang and Wong 2004). A possible reason for this could be the opportunity cost of human capital, since higher education levels may lead to lucrative career opportunities in large existing firms.

To reconcile the opposing views that the level of education is positively and negatively associated with entrepreneurial intention, it worth citing the work of Dickson et al. (2008). In their review of research on the role of education in entrepreneurship selection (intention) and success, the authors summarise the empirical evidence of previous studies and conclude that, especially in emerging economies, there is a nonlinear relationship between individuals' level of education and their entrepreneurial intention. According to this nonlinear relationship, higher levels of education are associated with higher levels of entrepreneurial intention; but individuals with very high levels of education are more likely to pursue a formal career.

In a study in the field of education (Khezrlou 2012), it was found that higher education levels were linked to higher cognitive awareness. Based on a cognitive-developmental model in which emotional awareness increases in a similar fashion to intellectual functions, Nandrino et al. (2013) conducted their study on unemployed adults and students. They clearly found that the level of emotional and cognitive awareness is significantly lower in subjects without a high school diploma (baccalaureate) than in subjects with higher levels of education. This is in agreement with Evans et al. (1993) who had already found that individuals with fewer years of formal education consistently display lower levels in their cognitive function, independent of age, birthplace, language of interview, occupation, and income. These prospective findings suggest that low educational attainment or a correlate predicts 
cognitive decline (Evans et al. 1993). Based on the above, we postulate that the level of education moderates the relationship between cognitive adaptability and entrepreneurial intention. The following is hypothesised:

H2: The level of education moderates the relationship between the five dimensions of cognitive adaptability and entrepreneurial intention.

\section{Age as a moderator}

Research on the relationship between age and entrepreneurial intention reports conflicting results. For instance, on the one hand some scholars such as Schwarz et al. (2009) observed that younger individuals display lower levels of entrepreneurial intention. Such young individuals usually do not have any precise plans regarding their occupational future or any knowledge about the nature of entrepreneurship at that time. On the other hand, Levesque and Minniti (2006), as well as Kautonen et al. (2010) disagree and argue that, as individuals get older, they find starting a new firm relatively less desirable, have lower entrepreneurial intention levels, and face higher opportunity cost of time. Schwarz et al. (2009) similarly argue that entrepreneurial intention declines when individuals exceed the age of 35 . This might be due to the fact that uncertainty avoidance of individuals usually increases in the course of time, owing to an increased consciousness about potential risks.

In the field of education, Khezrlou (2012) found that an older person is more cognitively aware than a younger individual. Analogously, Haynie and Shepherd (2009) posit that metacognitive processes become more crystallised and engrained the older an individual gets, and translate into more automatic, heuristic-based processes. Based on the above, we set out to determine whether age moderates the relationship between cognitive adaptability and entrepreneurial intention in the present context of investigation. The following is hypothesised:

H3: Age moderates the relationship between the five dimensions of cognitive adaptability and entrepreneurial intention.

\section{Gender as a moderator}

In a study by Schwarz et al. (2009), male students had a higher intention toward entrepreneurship than female students. Previous research also suggests that male students have stronger entrepreneurial aspirations than females (Wang and Wong 2004). Further analysis discloses that female university students are less interested in entrepreneurship (Gupta et al. 2009), not because of their risk-averse attitude but due to the lack of entrepreneurial knowledge, as well as the possible influence of traditional gender stereotypes (Herrington and Kew 2016). According to Schwarz et al. (2009), there are different reasons for the lower intention and involvement to be self- 
employed among females. Firstly, women entrepreneurship is usually more constrained by limited financial and social resources (Harris and Gibson 2008; Van der Merwe 2002). Secondly, in many countries of the world, and especially across Sub-Saharan Africa, the failure rate among female entrepreneurs is higher than is the case for male business founders (Kelley et al. 2015). Thirdly, the issue of family planning cannot be neglected in the reasoning for the lower intention among females to establish a firm. However, in Africa, there is evidence that suggest that the entrepreneurial intention level of females is almost the same as for males (Kelly et al. 2015).

Sheorey and Mokhtari (2001) conducted an analysis on gender differences in cognitive awareness strategies and found that female students in general used certain strategies more frequently than did their male counterparts. A study by Nandrino et al. (2013) demonstrates an effect of gender, in that a higher expressivity and a better recognition of emotional expression were observed in women. They found that, from a very early age, girls are socialised to allocate more affective and cognitive resources to emotional information. In another study, Liliana and Lavinia (2011) indicate that there are some gender differences in metacognition. Already at a young age, it seems that boys and girls use their metacognitive knowledge and skills in the learning process differently. Dissimilar results were found in the study by Ayazgök and Aslan (2014), which surveyed female and male students in the fields of science and mathematics, and where there was no statistically significant difference between male and female students regarding metacognitive awareness. This result is consistent with other studies in the literature (O'Neil and Brown 1998). Based on the above mixed evidence and the ensuing need for further research, we explore the moderating role of gender in the relationship between cognitive adaptability and entrepreneurial intention by testing the following hypothesis:

H4: Gender moderates the relationship between the five dimensions of cognitive adaptability and entrepreneurial intention.

\section{Entrepreneurial type as a moderator}

Smith and Miner (1983) studied the phenomenon of entrepreneurial types and identified the term 'craftsman entrepreneur', which was characterised by narrowness in education and training as well as low social awareness and involvement. The other type they recognised was the 'opportunistic entrepreneur', who revealed breadth in education and training, high social awareness and involvement and orientation to the future. In later years, the craftsman entrepreneur was labelled as 'necessity entrepreneur' and the opportunistic entrepreneur as 'opportunity entrepreneur' (Ellis and Williams 2011; Hechavarria and Reynolds 2009; Williams 2009). 
The dichotomous nature of entrepreneurship categorisation into necessity-driven (also informal, off-thebooks or survivalist) and opportunity-driven entrepreneurs resulted in an array of dissimilar findings, opinions and reflections. Kelley et al. (2016) state in the 2015/2016 Global GEM report that necessity entrepreneurs are those who have entered self-employment because they have no better options for work; in other words, they start businesses to generate income for themselves and their families. Conversely, opportunity entrepreneurs have chosen to start businesses arising from an opportunity, even when they have other employment possibilities. According to Herrington and Kew (2016), South Africa's opportunity-driven activity rates increased from 63.7 per cent in 2009 to 65.7 per cent in 2016. Currently, the number of new jobs that are created, on average, by opportunity-driven businesses in the early-stage entrepreneurial phase is 9.2 jobs per firm, compared to 3.4 jobs for necessity-driven firms.

Urban (2012a) suggests that it is likely that opportunity-driven rather than necessity-driven individuals, with higher levels of human capital, will have higher-order, cognitive processes. Ko (2012) supports the notion that individuals with a high need for cognition are likely to immerse themselves in cognitive activities, which in turn heighten the propensity of alertness, resulting in entrepreneurial opportunity identification. Need for cognition appears to be a necessary but insufficient condition for identifying entrepreneurial opportunities from a motivation-based cognitive perspective. This suggests that entrepreneurs who are intrinsically motivated to engage in cognitive activities may not necessarily notice entrepreneurial opportunities, unless they are alert to cues that could trigger the identification of entrepreneurial opportunities.

In this study, the focus falls particularly on the differences between these entrepreneurial types in the context of South Africa as a developing or emerging market. Critical evidence (with socio-economic impact) on cognitive adaptability and entrepreneurial intention has not been gathered quantitatively in research for the necessity-driven and low educated spheres. Necessity-driven entrepreneurs perceive themselves as being a lost generation, with limited hope of formal employment and economic freedom. As Brewer and Gibson (2014) point out, necessity entrepreneurship is mistakenly analysed and documented in developed nations and should be compared and investigated in a more suitable developing context. Therefore, the context of investigation of the present study is particularly relevant, where both necessity- and opportunity-driven entrepreneurs may be found (Herrington and Kew 2016). Based on the above, we want to determine whether these two entrepreneurial types have an effect on the relationship between cognitive adaptability and entrepreneurial intention. The following is hypothesised:

H5: Entrepreneurial type moderates the relationship between the five dimensions of cognitive 
adaptability and entrepreneurial intention.

\section{Method}

To test the hypotheses of this paper, we collected the data through a quantitative data collection method, i.e. a survey, allowing us to measure respondents' cognitive adaptability and entrepreneurial intention levels. This survey methodology enabled us to then conduct an empirical analysis of the data. The testing of hypotheses about moderating effects was rendered possible through a group comparison design.

\section{Sample}

The present study surveyed potential entrepreneurs in South Africa. A potential entrepreneur may be defined as an individual who has discovered an opportunity but has not yet decided to exploit such opportunity (Shane and Venkataraman 2000). This definition situates the potential entrepreneur before the formation of an entrepreneurial intention (Krueger and Brazeal 1994). Potential entrepreneurs were identified using a purposive sampling technique. The sampling frame was composed of individuals based in the Gauteng Province of South Africa and enrolled in different entrepreneurship education and training programs aimed at exposing participants to entrepreneurship and instilling entrepreneurial and business skills in them. Purposive sampling was used to identify the entrepreneurship programs, whereas each single program participant was randomly selected. Hardcopy surveys were distributed to 800 respondents and 769 responses were collected, resulting in 602 usable surveys.

In the course of the empirical investigation of the moderator variables, namely the level of education, age, gender, and entrepreneurial type, the sample was divided in sub-samples, enabling the investigation of moderators following the multi-group procedure described in later sections. Based on the nature of the moderator variable in question or the frequencies obtained for it, the sample was divided into the different sub-samples shown in Table 1. 
Table 1 Descriptive statistics

\begin{tabular}{|c|c|c|c|c|c|c|c|}
\hline \multirow{2}{*}{$\begin{array}{l}\text { Characteristics } \\
\text { Sample size }\end{array}$} & \multicolumn{2}{|c|}{ Total sample } & \multicolumn{2}{|c|}{ Necessity sample } & \multicolumn{2}{|c|}{$\begin{array}{c}\text { Opportunity } \\
\text { sample }\end{array}$} & \multirow{2}{*}{$\begin{array}{c}\text { Missing } \\
0\end{array}$} \\
\hline & 602 & & 443 & $73.6 \%$ & 159 & $26.4 \%$ & \\
\hline $\begin{array}{l}\text { Level of education } \\
\text { completed }\end{array}$ & & & 442 & & 159 & & 1 \\
\hline Secondary & 234 & $38.9 \%$ & 231 & $52.3 \%$ & 3 & $1.9 \%$ & \\
\hline Post-secondary & 367 & $61.1 \%$ & 211 & $47.7 \%$ & 156 & $98.1 \%$ & \\
\hline Age & & & 420 & & 148 & & 34 \\
\hline Up to 30 years & 229 & $38.1 \%$ & 204 & $46.2 \%$ & 25 & $15.7 \%$ & \\
\hline 30 years and older & 339 & $56.4 \%$ & 216 & $48.9 \%$ & 123 & $77.4 \%$ & \\
\hline Gender & & & 442 & & 159 & & 1 \\
\hline Female & 339 & $56.4 \%$ & 286 & $64.7 \%$ & 53 & $33.3 \%$ & \\
\hline Male & 262 & $43.6 \%$ & 156 & $35.3 \%$ & 106 & $66.7 \%$ & \\
\hline
\end{tabular}

The sub-sampling criterion for opportunity- and necessity-driven potential entrepreneurs follows the conceptualisation described in the theoretical model section and deserves a brief description. The opportunitydriven potential entrepreneur sub-sample was composed of MBA students who chose to enrol in an entrepreneurship education program, while the necessity-driven potential entrepreneur sample was represented by individuals in informal settlements who were urged to undergo an entrepreneurial skills development program aimed at unemployed individuals and with limited exposure to formal education, after which they had to register their cooperatives and start their ventures. The following paragraph illustrates the entrepreneurship program from which the necessity-driven potential entrepreneur sample was drawn.

In 2015, in an effort to decrease the unemployment rate in South Africa, the government provided funding to train and mentor unemployed individuals on how to start a business. More females than males were added to the lists of beneficiaries in an attempt to increase the level of entrepreneurial activity amongst women in South Africa. The local government of the Gauteng Province provided lists of unemployed individuals who qualified for the training; thereafter, the Chair in Entrepreneurship at the University of Pretoria conducted a fiveday cooperative training program. For the purposes of the present study, the survey was administered at the end of the five-day cooperative training program, at which point in time the program did not yet envisage the business start-up phase.

The two potential entrepreneur sub-samples differ in the sense that the opportunity-driven group chose to attend an entrepreneurship program and has a university degree (MBA students, with the aim to become entrepreneurs), while the necessity-driven group is unemployed and less educated, urged by the local government to undergo a training program and start a business. This distinction, based on respondents' motivation for enrolling in their respective entrepreneurship programs, mirrors the distinction between opportunity-driven and necessity- 
driven entrepreneurship found in the literature and introduced in an earlier section of this paper. Considered collectively, the two chosen samples provide diverse perspectives on the hypothesised moderation effect of entrepreneurial type on the relationship between cognitive adaptability and entrepreneurial intention. Jick (1979) argued that triangulation of results across diverse samples lends credibility to research findings.

The data screening procedure entailed removing cases with a high number of missing values and removing unresponsive cases. This brought the final size of the sample to 602, as reflected in Table 1. Missing values were replaced with median values on a case-by-case basis across constructs. This procedure for dealing with missing data takes into account a possible skewness in the data, thus giving a better estimate of central tendency.

As shown in Table 1, 443 respondents were necessity-driven entrepreneurs and 159 were opportunitydriven entrepreneurs. The majority of respondents $(61 \%)$ had a post-secondary qualification, and largely dominated the opportunity-driven sub-sample. In terms of age, while the overall sample was fairly evenly split between those younger than 30 and those 30 years old and older, the opportunity-driven sub-sample was mainly represented by people 30 years old and older. Since the majority of the sample (56.4\%) was represented by female potential entrepreneurs, it is important to note that the level of entrepreneurial intention in Africa has almost approached gender equity, and that the ratio of female to male entrepreneurial intention is 0.9 in this region of the world (Kelley et al. 2015). The necessity-driven sub-sample had a higher proportion of females, which reflects the government's deliberate efforts to train more unemployed women than men, while the opportunity-driven subsample had a higher proportion of males.

\section{Measures}

\section{Dependent variable}

The individual entrepreneurial intention scale (IEIS) by Thompson (2009) was used to operationalize entrepreneurial intention. The ten-item scale was developed with indicators measured on a continuous scale. Respondents are asked to rate their level of agreement with each statement by using a 4-point symmetrical Likert type scale ( $1=$ 'very untrue', $4=$ 'very true'). Three of the items (items 4,7 and 9$)$ in the scale are negatively worded and were reverse scored. This scale has yielded an average Cronbach's alpha coefficient of 0.86 across five independent student samples (Thompson 2009). The temporal stability of the IEIS has also reported satisfactory results across same-day, 1-month, 2-month, and 6-month retest occasions. From a construct validity 
perspective, the uni-dimensionality of the scale has been previously confirmed using student and non-student samples (Thompson 2009).

\section{Independent variables}

The 36-item measure of generalized Measure of Adaptive Cognition (MAC) by Haynie and Shepherd (2009) was used to measure the five dimensions of cognitive adaptability, namely, goal orientation, metacognitive knowledge, metacognitive experience, metacognitive choice, and monitoring. As recommended by Haynie and Shepherd (2009), the items were randomised when the instrument was administered. Respondents were asked to rate their level of agreement with each statement by using a 6-point symmetrical Likert type scale ranging from 1 ('not very much like me') to 7 ('very much like me'). A typical item reads as follows, 'I try to use strategies that have worked in the past.'

\section{Moderators}

The level of education refers to the highest level of education that a respondent is in possession of or has completed, such as a secondary school diploma or a university degree, and was measured on an ordinal scale. Age was measured on a ratio scale, by asking respondents an open-ended question about their age, while gender was measured on a nominal scale. The entrepreneurial type variable was categorised according to the explanation above by means of the two entrepreneurial types, namely necessity potential entrepreneurs and opportunity potential entrepreneurs, and was thus measured on a nominal scale.

\section{Analytical procedures}

\section{Reliability analysis}

The dependent variable (entrepreneurial intention) and the independent variables (the five dimensions of cognitive adaptability) represented constructs measured on interval (Likert) scales. Therefore, it was necessary to test the internal consistency reliability of their respective measures. For this purpose, we inspected the corrected interitem total correlation of the items within each scale, removing items with values lower than 0.3 , which are indicative that a particular item does not correlate very well with the scale (Field 2013).

We subsequently ran EFA to verify the five-factor structure of the MAC scale found by Haynie and Shepherd (2009), as well as the uni-dimensional structure of the IEIS scale found by Urban (2012a). The objective of this procedure was to uncover the underlying factor structure. Firstly, we checked for communalities, excluding 
items with loadings lower than 0.2 . Then we examined and removed high cross loadings. Finally, we detected the loadings again and removed loadings lower than 0.4. At this stage, we ran the EFA for the MAC scale, using the principal axis factoring (PAF) extraction method and the promax rotation method. The Kaiser-Meyer-Olkin measure of sampling adequacy being adequate (0.599) and Bartlett's test of sphericity being highly significant $(\mathrm{p}=0.000)$, both indicated that a factor analysis was appropriate. The EFA revealed the existence of five factors, explaining $39 \%$ of the variance in the data. After these procedures, each factor was measured by two items belonging to one of the cognitive adaptability dimension scales. Therefore, these five factors correspond to the five cognitive adaptability dimensions.

An EFA was also run on the items measuring entrepreneurial intention. After checking for communalities and removing items with loadings lower than 0.2, we ran an EFA with PAF extraction and promax rotation. The Kaiser-Meyer-Olkin measure of sampling adequacy being high (0.768) and Bartlett's test of sphericity being highly significant $(\mathrm{p}=0.000)$, both indicated that a factor analysis was appropriate. The resulting factor had five items and explained $32 \%$ of the variance.

Next, we next calculated the constructs' internal consistency reliability. For scales comprising a small number of items, it may be more appropriate to report the mean inter-item correlation (IIC) for the items (Pallant 2010), which should range between 0.2 and 0.4 (Briggs and Cheek 1986). The means, standard deviations, ICC values and Pearson correlations of the independent variables and of the dependent variable investigated in this study are presented in Table 2.

\section{Measurement model}

Each of the five cognitive adaptability dimensions, as well as entrepreneurial intention, were treated as latent variables as they were not observed directly, but were measured through observed indicators via CFA measurement models (Schumacker and Lomax 2010). Accordingly, we used CFA to verify that the hypothesised structure underlying this set of latent variables has a good fit. 
Table 2 Descriptive statistics, reliability, and zero-order correlations

\begin{tabular}{|c|c|c|c|c|c|c|c|c|c|}
\hline Variable & Mean & S.D. & ICC & 1 & 2 & 3 & 4 & 5 & 6 \\
\hline 1. Goal orientation & 3.32 & 0.40 & 0.21 & 1 & & & & & \\
\hline 2. Metacognitive knowledge & 3.24 & 0.42 & 0.21 & $0.311 * *$ & 1 & & & & \\
\hline 3. Metacognitive experience & 2.97 & 0.55 & 0.26 & $0.085^{*}$ & $0.228 * *$ & 1 & & & \\
\hline 4. Metacognitive choice & 3,17 & 0.47 & 0.22 & $0.268^{* *}$ & $0.428 * *$ & $0.095 *$ & 1 & & \\
\hline 5. Monitoring & 3.18 & 0.46 & 0.23 & $0.275^{* *}$ & $0.382 * *$ & $0.108 * *$ & $0.270 * *$ & 1 & \\
\hline 6. Entrepreneurial intention & 3.04 & 0.45 & 0.21 & $0.294 * *$ & $0.185 * *$ & 0.080 & $0.163 * *$ & 0.030 & 1 \\
\hline
\end{tabular}

Notes: $* * \mathrm{p}<0.01, * \mathrm{p}<0.05$ 


\section{Structural model}

To test the hypothesised relationships between the cognitive adaptability dimensions and entrepreneurial intention, and the influence exerted by the moderators advanced in this paper, we conducted structural equation modelling. To test H1, we specified a structural model where goal orientation, metacognitive knowledge, metacognitive experience, metacognitive choice, and monitoring are independent variables, and entrepreneurial intention is the dependent variable. We tested this structural model using path analysis, whereby the constructs were inserted as observed variables and the structural model was therefore just-identified (Schumacker and Lomax 2010). Then, to test $\mathrm{H} 2-5$, where the level of education, age, gender, and entrepreneurial type act as moderators of the relationship between the five cognitive adaptability dimensions and entrepreneurial intention, we followed a multi-group approach with SEM. This approach was applied owing to the fact that the overall sample was subgrouped according to these moderating variables, thus allowing for the analysis to be conducted for different groups or samples. The main objective of a multi-group approach in SEM is to ascertain whether or not the components of the structural model are invariant across groups. Should a component vary across groups, its path is moderated by the categorical variable in question. The multi-group analysis was performed using the chi-square difference test to verify which variables were moderators and which specific SEM paths were moderated, while the critical ratios test was employed to gain deeper insights into the moderating effects.

\section{Results}

\section{Confirmatory factor analysis (CFA)}

The results of the CFA for the measurement model are summarised in Table 3. Absolute fit indices such as the $\chi^{2}$ statistic, the goodness-of-fit (GFI) index, the root mean square error of approximation (RMSEA), and the normed chi-square all concur in indicating that the measurement model provides an adequate fit to the data. The comparative fit index (CFI) and the adjusted goodness-of-fit index (AGFI), which represent an incremental and a parsimony fit index, respectively, also indicated a good fit. Therefore, structural model testing could be addressed next. 
Table 3 Goodness-of-fit statistics

\begin{tabular}{lllllllll} 
Measurement Model & $\boldsymbol{\chi}^{\mathbf{2}}$ & $\mathbf{d f}$ & $\boldsymbol{p}$ value & $\boldsymbol{\chi}^{\mathbf{2}} / \mathbf{d f}$ & GFI & RMSEA & CFI & AGFI \\
\hline Statistic & 95.161 & 75 & 0.058 & 1.269 & 0.979 & 0.021 & 0.981 & 0.967 \\
Recommended value* & & & $\begin{array}{l}<0.05 \\
\text { possible }\end{array}$ & $<3.0$ & $\geq 0.95$ & $<0.07$ & $\geq 0.92$ & $\geq 0.90$
\end{tabular}

* According to sample size and number of observed indicators, based on Hair et al. (2010) and Schumacker and Lomax (2010)

\section{Structural model testing}

In $\mathrm{H} 1$, we hypothesised a positive relationship between the five dimensions of cognitive adaptability and entrepreneurial intention. As shown in Table 4, which provides a summary of the path estimates for the structural model, goal orientation, metacognitive experience, and metacognitive choice all had a positive directional relationship with entrepreneurial intention, where goal orientation has the strongest positive relationship (with a critical ratio of 5.603 at the $\mathrm{p}<0.01$ level). Monitoring had a negative causal relationship with entrepreneurial intention at the $\mathrm{p}<0.01$ level, while the relationship between metacognitive knowledge and entrepreneurial intention was statistically non-significant. Therefore, we found partial support for H1, as only the cognitive adaptability dimensions of goal orientation, metacognitive experience, and metacognitive choice had a positive relationship with entrepreneurial intention.

Table 4 Structural equation model results: path estimates

\begin{tabular}{lcl} 
Path & $\boldsymbol{\beta}$ & C.R. \\
\hline Goal orientation $\rightarrow$ EI & 0.288 & $5.603^{* * *}$ \\
Metacognitive knowledge $\rightarrow$ EI & 0.043 & 0.867 \\
Metacognitive experience $\rightarrow$ EI & 0.085 & $2.008^{* *}$ \\
Metacognitive choice $\rightarrow$ EI & 0.105 & $2.327^{* *}$ \\
Monitoring $\rightarrow$ EI & -0.205 & $-3.844^{* * *}$
\end{tabular}

Notes: $\beta$ : standardised estimate; C.R.: critical ratio; $* * * \mathrm{p}<0.01 ; * * \mathrm{p}<0.05$ 
Table 5 Multi-group analysis of structural models: chi-square difference test and critical ratios test results

\begin{tabular}{|c|c|c|c|c|c|c|c|c|}
\hline \multirow{2}{*}{ Path } & \multicolumn{2}{|c|}{$\begin{array}{l}\text { Level of education: secondary } \\
\text { vs. post-secondary }\end{array}$} & \multicolumn{2}{|c|}{ Age: under 30 vs. 30 and older } & \multicolumn{2}{|c|}{ Gender: male vs. female } & \multicolumn{2}{|c|}{$\begin{array}{c}\text { Entrepreneurial type: } \\
\text { necessity vs. opportunity }\end{array}$} \\
\hline & $\chi^{2}(\mathrm{df})$ & z value & $\chi^{2}(\mathrm{df})$ & $\mathrm{z}$ value & $\chi^{2}(\mathbf{d f})$ & $\mathrm{z}$ value & $\chi^{2}(\mathrm{df})$ & z value \\
\hline All (full model) & $16.756(5)^{* * *}$ & & $1.754(5)$ & & $19.687(5)^{* * *}$ & & $12.015(5)^{* *}$ & \\
\hline Goal orientation $\rightarrow$ EI & $4.550(1)^{* *}$ & $2.139 * *$ & $0.393(1)$ & 0.627 & $4.542(1)^{* *}$ & $2.135 * *$ & $0.491(1)$ & -0.701 \\
\hline Metacognitive knowledge $\rightarrow$ EI & $0.531(1)$ & -0.729 & $0.850(1)$ & 0.922 & $2.810(1)^{*}$ & $1.678^{*}$ & $0.132(1)$ & -0.364 \\
\hline Metacognitive experience $\rightarrow$ EI & $7.325(1) * * *$ & $-2.178 * * *$ & $0.495(1)$ & -0.704 & $0.180(1)$ & 0.425 & $6.644(1)^{* *}$ & $-2.591 * * *$ \\
\hline Metacognitive choice $\rightarrow$ EI & $1.670(1)$ & 1.294 & $0.003(1)$ & -0.059 & $0.427(1)$ & -0.653 & $1.232(1)$ & 1.111 \\
\hline Monitoring $\rightarrow$ EI & $1.386(1)$ & -1.178 & $0.569(1)$ & -0.755 & $17.328(1)^{* * *}$ & $-4.194 * * *$ & $2.215(1)$ & 1.491 \\
\hline
\end{tabular}

Notes: $* * * \mathrm{p}<0.01 ; * * \mathrm{p}<0.05 ; * \mathrm{p}<0.10$ 


\section{Moderator analysis}

In $\mathrm{H} 2-5$ we hypothesised the moderating effect of level of education, age, gender, and entrepreneurial type on the relationship between the five cognitive adaptability dimensions and entrepreneurial intention. To test these hypotheses, we used the structural model of the relationship between the five cognitive adaptability dimensions and entrepreneurial intention as the base model and performed a multi-group analysis for each moderator. The results of constraining various aspects of the model to be equal as a means to determine sources of invariance are presented in Table 5 .

In regard to the level of education as a moderator, the chi-square difference test revealed that this variable is not group invariant; therefore, a possible moderation at the individual path level was explored. The chi-square difference test at the path level showed that level of education was a moderator of the effect of goal orientation and metacognitive experience on entrepreneurial intention. More specifically, for higher levels of education, the positive influence of goal orientation on entrepreneurial intention was stronger ( $\mathrm{z}$ value $=2.139)$. Conversely, the positive influence of metacognitive experience on entrepreneurial intention was stronger for lower levels of education $(\mathrm{z}$ value $=-2.718)$. Hence, $\mathrm{H} 2$ was supported for goal orientation and metacognitive experience.

Turning to age, the chi-square difference test showed invariance both at the model and individual path levels, as there were no statistically significant differences. Therefore, age was not a moderator of the relationship between the five cognitive adaptability dimensions and entrepreneurial intention, and H3 was not supported.

The chi-square difference test displayed a moderating effect pertaining to gender at the model level. At the path level, gender had a moderating effect with respect to goal orientation and monitoring. The effect of gender on the relationship between metacognitive knowledge was not considered, as the path between metacognitive knowledge and entrepreneurial intention was not statistically significant in the structural model. The critical ratios test provided more details about the moderating role of gender. In particular, the positive influence of goal orientation on entrepreneurial intention was stronger for females $(\mathrm{z}$ value $=2.135)$, while the influence of monitoring was weak, but positive, for males $(\beta=0.042)$ and turned to strong, and negative, for females ( $\beta=-$ 0.395; $\mathrm{z}$ value $=-4.194)$. Hence, there was support for $\mathrm{H} 4$ in regard to goal orientation and monitoring.

Finally, as shown in Table 5, entrepreneurial type also exhibited a moderating effect at the model level, according to the chi-square difference test. However, only the path between metacognitive experience and entrepreneurial intention was moderated by entrepreneurial type, so that the positive influence of metacognitive experience on entrepreneurial intention was stronger for necessity entrepreneurs ( $\mathrm{z}$ value $=-2.591$ ). H5 was thus supported only with respect to metacognitive experience. 


\section{Discussion and conclusion}

It is clear from the theoretical foundation presented in this paper that there is limited evidence on the relationship between entrepreneurial intention and each of the five cognitive adaptability dimensions; therefore, the purpose of this paper was to provide evidence of such a relationship. Furthermore, we introduced personal-level moderators to examine the effect of level of education, age, gender and entrepreneurial type on this relationship.

Our findings align with those of Urban (2012a) and confirm the validity of the five-factor structure of cognitive adaptability across necessity- and opportunity-driven potential entrepreneurs in an emerging economy. A significant contribution of this study lies in measuring the dimensions of cognitive adaptability individually as opposed to being treated as one construct. The finding that goal orientation, metacognitive experience, and metacognitive choice exert a positive influence on the formation of entrepreneurial intention holds potential for the identification and inculcation of cognitive mechanisms that trigger the intentionality aspect of entrepreneurship. It is noteworthy that we found a non-significant relationship between metacognitive knowledge and entrepreneurial intention, yet in the study by Urban (2012a, 2012b) this was the only dimension that indicated a significant relationship with entrepreneurial intention. One explanation for this could lie in the use of different samples. Urban surveyed an entrepreneurial group with a tertiary qualification, while the majority of our sample was represented by necessity potential entrepreneurs holding a secondary qualification. The highly significant negative relationship between entrepreneurial intention and monitoring we observed is in contrast with extant literature (Baron 2007). A possible interpretation of the present finding could lie in the context of investigation, namely a developing country, where high levels of necessity entrepreneurship are usually found (Herrington and Kew 2016). As monitoring entails the constant re-evaluation of one's purpose and performance, this cognitive activity could lead individuals in a developing-country context to re-evaluate their reasons for being self-employed and to eventually move to formal employment, once their survivalist motives are overcome. Many countries are spending huge amounts of money of training, developing and supporting entrepreneurs but we know little about the way entrepreneurs adapt in this uncertain environment. Understanding how the five dimensions of cognitive adaptability influence entrepreneurial intention can assist policy makers to pay attention to the individual dimensions of cognitive adaptability in an entrepreneurial education context. Furthermore, educators should include the three dimensions of goal orientation, metacognitive experience, and metacognitive choice in the curricula of entrepreneurship training programs to foster higher levels of entrepreneurial intention, especially where more necessity potential entrepreneurs are present. 
For most of the moderators, dissimilar results were found in previous studies focusing on the individual constructs of entrepreneurial intention and cognitive adaptability. This study provides more insight into the cognitive adaptability dimensions whose positive effect on entrepreneurial intention is influenced by the moderators investigated in this paper. Goal orientation and metacognitive experience were the only two cognitive adaptability dimensions that were moderated by respondents' level of education. For higher levels of education the effect of goal orientation on entrepreneurial intention was stronger. Previous studies already confirmed the association between high levels of education and high levels of entrepreneurial intention (Turker and Sonmez Selçuk 2009), as well as between high levels of cognitive awareness and entrepreneurial intention (Evans et al. 1993; Khezrlou 2012). The present study, therefore, advanced the theory behind these relationships, as it empirically tested the link between cognitive adaptability, entrepreneurial intention, and the level of education simultaneously. It can be postulated that individuals with higher levels of education, which is associated with corresponding higher levels of cognitive awareness, elaborate contextual information and assign meaning to such information - the task of goal orientation - in a more effective way in directing it to their perceived ability to start a business. This cognitive process thus may lead such individuals to form an entrepreneurial intention more firmly. For respondents with relatively low levels of education, the effect of metacognitive experience on entrepreneurial intention was stronger. We can therefore conclude that, at lower levels of education, individuals rely more on their intuitive experience in formulating strategies and accomplishing their goals (Haynie and Shepherd 2009), as opposed to relying on their competences acquired from formal education. This greater predisposition for intuition and pre-reflection about strategies, which characterises metacognitive experience, in less educated individuals may be more tightly associated with entrepreneurship, which relies on similar cognitive processes when it comes to making decisions in an uncertain environment. The implication of this finding is that cognitive adaptability can be fostered even at early school years to promote entrepreneurial intention among individuals who are less educated.

However, age was not a moderator in the relationship between any of the cognitive adaptability dimensions and entrepreneurial intention. Therefore, cognitive adaptability dimensions seem to influence individuals who are less educated but not necessarily younger. Our finding is different from the findings of Schwarz et al. (2009), who observed that individuals younger than the age of 35 display lower levels of entrepreneurial intention, and Kautonen et al. (2010) and Levesque and Minniti (2006), who reported that older individuals display lower levels of entrepreneurial intention. The findings pertaining to age are also in disagreement with Khezrlou (2012), who observed that an older person is more cognitively aware than a younger 
individual, which hints at a possible role played by age in cognitive adaptability-related frameworks. This finding is particularly relevant, in that it may signify that the possession of the five cognitive adaptability dimensions triggers an effect (or non-effect, depending on the cognitive adaptability dimension in question) on entrepreneurial intention irrespective of the age of the individual.

Goal orientation and monitoring were the only two cognitive adaptability dimensions that were moderated by gender. A stronger relationship between goal orientation and entrepreneurial intention was found for females than for males. This is in agreement with cognitive adaptability literature where scholars such as Liliana and Lavinia (2011), Nandrino et al. (2013) and Sheorey and Mokhtari (2001) indicate that there are some gender differences in metacognition and that females are more cognitively adaptable than males. However, Ayazgök and Aslan (2014) and O'Neil and Brown (1998) found in their studies no statistically significant difference between male and female students regarding metacognitive awareness. The findings of the present study may allude to the fact that females elaborate and assign meaning to information from their surroundings more consciously, which is one of the mechanisms followed to form intentions (Urban, 2012b). The relationship between monitoring and entrepreneurial intention was stronger and negative for females, while being weak and positive for males. As there is evidence that females are more cognitively adaptable than males (Nandrino et al. 2013), the higher impact of monitoring on entrepreneurial intention for females is not surprising. Yet, as for the negative direction of the effect of monitoring, we can postulate that, in the light of the constraints faced by females, which make them less entrepreneurially inclined, monitoring, with its associated processes of constant reassessment of one's motives, performance and environment, hinders females in the development of entrepreneurial intention. As already acknowledged in the method section, the majority of our sample consisted of females. One the one hand, this arouses a point of caution, as females present lower entrepreneurial activity levels than males (Gupta et al 2009). However, as the level of female entrepreneurial intention almost matches the level of male entrepreneurial intention in Africa (Kelley et al. 2015), this study offers insights into the cognitive mechanisms that may encourage or hinder the development of an entrepreneurial intention in women.

Metacognitive experience proved to be the only cognitive adaptability dimension that was moderated by entrepreneurial type. The positive influence of metacognitive experience on entrepreneurial intention was stronger for the necessity potential sample than for the opportunity potential sample. This result differs from the findings of Baptista et al. (2014), Ko (2012) and Urban (2012a), who suggest that it is likely that opportunity-driven, rather than necessity-driven individuals have higher-order cognitive processes. However, this finding suggests that intuition-based cognitive processes, such as metacognitive experience, contribute more to the development of 
entrepreneurial intention in necessity-driven entrepreneurs. As these are pushed into entrepreneurship by an unfavourable life situation, and as metacognitive experience is developed in the context of unsuccessful performance of tasks (Haynie and Shepherd 2009), one might expect this to occur.

\section{Study limitations and recommendations}

No study is without limitations. Firstly, the sub-samples used for the multi-group moderator analysis could have been more equally representative. Owing to the exploratory nature of the investigation of moderators, only a few demographic variables were introduced as moderators in the relationship between cognitive adaptability and entrepreneurial intention. In future research, additional potential moderators could be examined. Goal orientation, metacognitive experience and monitoring were the only cognitive adaptability dimensions for which the relationship with entrepreneurial intention was moderated. More analyses are needed on the relationship between metacognitive choice, knowledge and entrepreneurial intention.

Our findings apply primarily to developing country contexts similar to that of South Africa. This study did not examine the relationship between cognitive adaptability dimensions and entrepreneurial intention from an advanced economy perspective; hence, the avenue of investigating how results would differ in a developed country context is open for future research. The majority of existing studies only reflect upon entrepreneurial behaviour in developed nations and there is thus a need for further investigation into the realm of necessity within developing nations. This holds potential for expanding current theory. Southern Africa explicitly represents an environment where the advancement of the body of knowledge within resource-driven, as well as efficiencydriven economies, is present. Even though we tested our model with data from South Africa, we do believe the findings of the present study have relevance for advanced countries, particularly the importance of paying attention to cognitive adaptability in the training and development of potential entrepreneurs. Both advanced and emerging countries have a collective interest in fostering entrepreneurship for economic growth. Most existing studies fail to consider potential cross-country differences and do not clearly separate situations of opportunity entrepreneurship from necessity entrepreneurship, causing inconsistencies (Solomon et al. 2008). Future studies could focus on a comparison of developed and developing countries' results on the relationship between cognitive adaptability and entrepreneurial intention.

As we have already acknowledged in previous sections, the majority of this study's respondents was represented by female potential entrepreneurs. This should not impinge on the validity and generalizability of the findings to the context of investigation, as there is evidence that entrepreneurial intention levels in Africa are 
comparable across genders (Kelley et al. 2015). Furthermore, it could be interesting to determine why the entrepreneurial intention levels of females and males are more similar in Africa than in developed countries.

Entrepreneurship students normally portray high levels of entrepreneurial intention, but the graduate start-up rate is relatively low (Galloway and Brown 2002). The implication for practice encapsulates that universities and other training institutions should include cognitive adaptability in their entrepreneurship education and training curricula to ensure that cognitive awareness is enforced as one of the key drivers to assist students to develop an entrepreneurial intention. Understanding metacognitive adaptability can assist national policy makers who try to encourage more opportunity-focused entrepreneurial behaviour in South Africa (Urban 2012a). Considering the proliferation of research on cognitive adaptability, more work needs to be done on improving the measurement quality of the scale. The concepts hold much benefit both as a theoretical model and practical framework to cultivate high potential opportunity entrepreneurs.

\section{References}

Acs, Z. J., Desai, S., \& Hessels, J. (2008). Entrepreneurship, economic development and institutions. Small Business Economics, 31(3), 219-234.

Acs, Z. J., \& Varga, A. (2005). Entrepreneurship, agglomeration and technological change. Small Business Economics, 24(3), 323-334.

Ajzen, I. (1991). The theory of planned behavior. Organizational Behavior and Human Decision Processes, $50(2), 179-211$.

Akbaria, R., Khayerb, M., \& Abedi, J. (2014). Studying effect of educating state metacognition on learning mathematics. Reef Resources Assessment and Management Technical Paper, 40(2), 220-229.

Ayazgök, B., \& Aslan, H. (2014). The review of academic perception, level of metacognitive awareness and reflective thinking skills of science and mathematic university students. Procedia-Social and Behavioral Sciences, 141, 781-790.

Bandura, A. (1986). Social foundations of thought and action: A social cognitive theory. Englewood Cliffs, USA: Prentice-Hall.

Baptista, R., Karaöz, M., \& Mendonça, J. (2014). The impact of human capital on the early success of necessity versus opportunity-based entrepreneurs. Small Business Economics, 42(4), 831-847.

Baron, R. A. (2007). Behavioral and cognitive factors in entrepreneurship: Entrepreneurs as the active element in new venture creation. Strategic Entrepreneurship Journal, 1(1-2), 167-182. 
Baron, R. A., \& Ward, T. B. (2004). Expanding entrepreneurial cognition's toolbox: Potential contributions from the field of cognitive science. Entrepreneurship Theory and Practice, 28(6), 553-573.

Baumol, W. J., \& Strom, R. J. (2007). Entrepreneurship and economic growth. Strategic Entrepreneurship Journal, 1(3-4), 233-237.

Block, J., \& Sandner, P. (2009). Necessity and opportunity entrepreneurs and their duration in self-employment: evidence from German micro data. Journal of Industry, Competition and Trade, 9(2), 117-137.

Brewer, J., \& Gibson, S. W. (2014). Necessity entrepreneurs: microenterprise education and economic development. Cheltenham: Edward Elgar Publishing.

Briggs, S. R., \& Cheek, J. M. (1986). The role of factor analysis in the development and evaluation of personality scales. Journal of personality, 54(1), 106-148.

Bruton, G. D., Ahlstrom, D., \& Obloj, K. (2008). Entrepreneurship in emerging economies: Where are we today and where should the research go in the future. Entrepreneurship Theory and Practice, 32(1), 1-14.

Bryant, P. T. (2006). Improving entrepreneurial education through self-regulatory skills. In 4th Annual Conference of the National Collegiate Inventors and Innovators Alliance (pp. 279-289). National Collegiate Inventors \& Innovators Alliance. http://search.proquest.com/openview/ de732bf62518c560ea3d1e67320a67e8/1?pq-origsite=gscholar. Accessed 5 August 2016

Corley, K. G., \& Gioia, D. A. (2011). Building theory about theory building: What constitutes a theoretical contribution? Academy of Management Review, 36(1), 12-32.

Dickson, P. H., Solomon, G. T., \& Weaver, K. M. (2008). Entrepreneurial selection and success: Does education matter? Journal of Small Business and Enterprise Development, 15(2), 239-258.

Ellis, K., \& Williams, C. (2011). Maximising impact of youth entrepreneurship support in different contexts: background report, framework and toolkit for consultation. London: Overseas Development Institute. http://led.co.za/sites/default/files/cabinet/orgname-raw/document/2013/7728.pdf. Accessed 5 August 2016

Evans, D. A., Beckett, L. A., Albert, M. S., Hebert, L. E., Scherr, P. A., Funkenstein, H. H., \& Taylor, J. O. (1993). Level of education and change in cognitive function in a community population of older persons. Annals of Epidemiology, 3(1), 71-77.

Fayolle, A., \& Liñán, F. (2014). The future of research on entrepreneurial intentions. Journal of Business Research, 67(5), 663-666.

Field, A. (2013). Discovering statistics using IBM SPSS Statistics (4th ed.). London: Sage. 
Flavell, J. H. (1971). First discussant's comments: What is memory development the development of?. Human Development, 14(4), 272-278.

Flavell, J. H. (1976). Metacognitive aspects of problem solving. In L.B. Resnick (Ed.), The nature of intelligence (pp. 231-236). Hillsdale, NJ: Erlbaum

Flavell, J. H. (1979). Metacognition and cognitive monitoring: A new area of cognitive-developmental inquiry. American psychologist, 34(10), 906.

Flavell, J. H. (1987). Speculations about the nature and development of metacognition. In FE Weinert \& RH Kluwe (Eds.), Metacognition, Motivation and Understanding (pp. 21-29). Hillside. New Jersey: Lawrence Erlbaum Associates.

Frith, C. (2012). Explaining delusions of control: The comparator model 20years on. Consciousness and Cognition, 21(1), 52-54.

Galloway, L., \& Brown, W. (2002). Entrepreneurship education at university: a driver in the creation of high growth firms? Education + Training, 44(8/9), 398-405.

Garavan, T. N., \& O’Cinneide, B. (1994). Entrepreneurship education and training programmes: A review and evaluation-Part 1. Journal of European Industrial Training, 18(8), 3-12.

George, G., Corbishley, C., Khayesi, J. N., Haas, M. R., \& Tihanyi, L. (2016). Bringing Africa in: Promising directions for management research. Academy of Management Journal, 59(2), 377-393.

George, N. M., Parida, V., Lahti, T., \& Wincent, J. (2016). A systematic literature review of entrepreneurial opportunity recognition: insights on influencing factors. International Entrepreneurship and Management Journal, 12(2), 309-350.

Griffin, D. W., \& Ross, L. (1991). Subjective construal, social inference, and human misunderstanding. Advances in Experimental Social Psychology, 24, 319-359.

Gupta, V. K., Turban, D. B., Wasti, S. A., \& Sikdar, A. (2009). The role of gender stereotypes in perceptions of entrepreneurs and intentions to become an entrepreneur. Entrepreneurship Theory and Practice, 33(2), $397-417$.

Harris, M., \& Gibson, S. (2008). An examination of the entrepreneurial attitudes of US versus Chinese students. The American Journal of Entrepreneurship, 1(1), 1-20.

Haynie, J. M., \& Shepherd, D. A. (2009). A measure of adaptive cognition for entrepreneurship research. Entrepreneurship Theory and Practice, 33(3), 695-714.Haynie, J. M., Shepherd, D., Mosakowski, E., 
\& Earley, P. C. (2010). A situated metacognitive model of the entrepreneurial mindset. Journal of business venturing, 25(2), 217-229.

Haynie, J. M., Shepherd, D. A., \& Patzelt, H. (2012). Cognitive adaptability and an entrepreneurial task: The role of metacognitive ability and feedback. Entrepreneurship Theory and Practice, 36(2), 237-265.

Hechavarria, D. M., \& Reynolds, P. D. (2009). Cultural norms \& business start-ups: the impact of national values on opportunity and necessity entrepreneurs. International Entrepreneurship and Management Journal, 5(4), 417-437.

Herrington, M., \& Kew, P. (2016). South African Report 2015/16: Is South Africa heading for an economic meltdown? Cape Town: Global Entrepreneurship Monitor. http://www.gemconsortium.org/report/ 49537. Accessed 26 June 2016.

Hills, G. E. (1988). Variations in university entrepreneurship education: An empirical study of an evolving field. Journal of Business Venturing, 3(2), 109-122.

Jick, T. D. (1979). Mixing qualitative and quantitative methods: Triangulation in action. Administrative Science Quarterly, 24(4), 602-611.

Kanfer, R. (1990). Motivation theory and industrial and organizational psychology. In M. D. Dunnette \& L. Hough (Eds.), Handbook of Industrial and Organizational Psychology (Vol. 1, pp. 75-170). Palo Alto: Consulting Psychologists Press.

Kautonen, T., Luoto, S., \& Tornikoski, E. T. (2010). Influence of work history on entrepreneurial intentions in "prime age" and "third age": A preliminary study. International Small Business Journal, 28(6), 583601.

Kelley, D., Brush, C., Greene, P., Herrington, M., Ali, A., \& Kew, P. (2015). Special report: Women's entrepreneurship. London: Global Entrepreneurship Research Association. http://www.gemconsortium.org/report/49281. Accessed 12 January 2017.

Kelley, D., Singer, S., \& Herrington, M. (2016). GEM 2015/2016 Global Report. London: Global Entrepreneurship Research Association. http://www.gemconsortium.org/report/49480. Accessed 14 April 2015.

Khezrlou, S. (2012). The relationship between cognitive and metacognitive strategies, age, and level of education. The Reading Matrix, 12(1), 50-61.

Ko, S. (2012). Entrepreneurial opportunity identification: a motivation-based cognitive approach. The Journal of Applied Management and Entrepreneurship, 17(2), 23. 
Kolvereid, L., \& Moen, Ø. (1997). Entrepreneurship among business graduates: does a major in entrepreneurship make a difference? Journal of European Industrial Training, 21(4), 154-160.

Kor, Y. Y., Mahoney, J. T., \& Michael, S. C. (2007). Resources, capabilities and entrepreneurial perceptions. Journal of Management Studies, 44(7), 1187-1212.

Krueger, N. F. J. (2003). The cognitive psychology of entrepreneurship. In Z. J. Acs \& D. B. Audretsch (Eds.), Handbook of Entrepreneurship Research (pp. 105-140). Great Britain: Kluwer Academic Publishers.

Krueger, N. F. J., \& Brazeal, D. V. (1994). Entrepreneurial potential and potential entrepreneurs. Entrepreneurship Theory and Practice, 18(3), 91-104.

Krueger, N. F. J., Reilly, M. D., \& Carsrud, A. L. (2000). Competing models of entrepreneurial intentions. Journal of Business Venturing, 15(5), 411-432.

Lanivich, S. E. (2015). The RICH entrepreneur: Using conservation of resources theory in contexts of uncertainty. Entrepreneurship Theory and Practice, 39(4), 863-894.

Levesque, M., \& Minniti, M. (2006). The effect of aging on entrepreneurial behavior. Journal of Business Venturing, 21(2), 177-194.

Liliana, C., \& Lavinia, H. (2011). Gender differences in metacognitive skills: a study of the 8th Grade pupils in Romania. Procedia-Social and Behavioral Sciences, 29, 396-401.

Liñán, F., \& Fayolle, A. (2015). A systematic literature review on entrepreneurial intentions: Citation, thematic analyses, and research agenda. International Entrepreneurship and Management Journal, 11(4), 907933.

Liñán, F., Rodríguez-Cohard, J. C., \& Rueda-Cantuche, J. M. (2011). Factors affecting entrepreneurial intention levels: a role for education. International Entrepreneurship and Management Journal, 7(2), 195-218.

Ling, J., \& Chok, J. I. (2013). The effects of organizational bureaucracy and capital constraints on the development of entrepreneurial cognitions. Journal of Applied Management and Entrepreneurship, $18(2), 3-20$.

Lüthje, C., \& Franke, N. (2003). The “making”of an entrepreneur: Testing a model of entrepreneurial intent among engineering students at MIT. R\&D Management, 33(2), 135-147.

Malmström, M., Johansson, J., \& Wincent, J. (2015). Cognitive constructions of low-profit and high-profit business models: A repertory grid study of serial entrepreneurs. Entrepreneurship Theory and Practice, 39(5), 1083-1109. 
Minniti, M., \& Nardone, C. (2007). Being in someone else's shoes: the role of gender in nascent entrepreneurship. Small Business Economics, 28(2-3), 223-238.

Mitchell, R. K., Smith, B., Seawright, K. W., \& Morse, E. A. (2000). Cross-cultural cognitions and the venture creation decision. Academy of Management Journal, 43(5), 974-993.

Nandrino, J.-L., Baracca, M., Antoine, P., Paget, V., Bydlowski, S., \& Carton, S. (2013). Level of emotional awareness in the general French population: Effects of gender, age, and education level. International Journal of Psychology, 48(6), 1072-1079.

Naudé, W. (2010). Entrepreneurship, developing countries, and development economics: New approaches and insights. Small Business Economics, 34(1), 1-12.

Naudé, W. (2011). Entrepreneurship and economic Development: An introduction. In Entrepreneurship and Economic Development (pp. 3-17). Palgrave Macmillan: UK.

O’Neil, Jr, H. F., \& Brown, R. S. (1998). Differential effects of question formats in math assessment on metacognition and affect. Applied Measurement in Education, 11(4), 331-351.

Pallant, J. (2010). SPSS survival manual: A step by step guide to data analysis using the SPSS program (4th ed.). Maidenhead: McGraw-Hill.

Piperopoulos, P., \& Dimov, D. (2015). Burst bubbles or build steam? Entrepreneurship education, entrepreneurial self-efficacy, and entrepreneurial intentions. Journal of Small Business Management, 53(4), 970-985.

Robinson, P. B., \& Sexton, E. A. (1994). The effect of education and experience on self-employment success. Journal of Business Venturing, 9(2), 141-156.

Saeed, S., Yousafzai, S. Y., Yani-De-Soriano, M., \& Muffatto, M. (2015). The role of perceived university support in the formation of students' entrepreneurial intention. Journal of Small Business Management, 53(4), 1127-1145.

Schacter, D. L. (1999). The seven sins of memory: Insights from psychology and cognitive neuroscience. American psychologist, 54(3), 182.

Schmidt, A. M., \& Ford, J. K. (2003). Learning within a learner control training environment: The interactive effects of goal orientation and metacognitive instruction on learning outcomes. Personnel Psychology, $56(2), 405-429$.

Schumacker, R. E., \& Lomax, R. G. (2010). A beginner's guide to structural equation modeling (3rd ed.). New York: Routledge. 
Schwarz, E. J., Wdowiak, M. A., Almer-Jarz, D. A., \& Breitenecker, R. J. (2009). The effects of attitudes and perceived environment conditions on students' entrepreneurial intent: An Austrian perspective. Education+ Training, 51(4), 272-291.

Shane, S., \& Venkataraman, S. (2000). The promise of entrepreneurship as a field of research. Academy of Management Review, 25(1), 217-226.

Shapero, A., \& Sokol, L. (1982). The social dimensions of entrepreneurship. In C. A. Kent, D. L. Sexton, \& K. H. Vesper (Eds.), Encyclopedia of Entrepreneurship (1st ed., pp. 72-90). Englewood Cliffs: PrenticeHall. Accessed 27 March 2013

Sheorey, R., \& Mokhtari, K. (2001). Differences in the metacognitive awareness of reading strategies among native and non-native readers. System, 29(4), 431-449.

Smith, N. R., \& Miner, J. B. (1983). Type of entrepreneur, type of firm, and managerial motivation: Implications for organizational life cycle theory. Strategic Management Journal, 4(4), 325-340.

Solomon, G., Dickson, P. H., Solomon, G. T., \& Weaver, K. M. (2008). Entrepreneurial selection and success: does education matter? Journal of Small Business and Enterprise Development, 15(2), 239-258.

Thompson, E. R. (2009). Individual entrepreneurial intent: Construct clarification and development of an internationally reliable metric. Entrepreneurship Theory and Practice, 33(3), 669-694.

Townsend, D. M., Busenitz, L. W., \& Arthurs, J. D. (2010). To start or not to start: Outcome and ability expectations in the decision to start a new venture. Journal of Business Venturing, 25(2), 192-202.

Turker, D., \& Sonmez Selçuk, S. (2009). Which factors affect entrepreneurial intention of university students? Journal of European Industrial Training, 33(2), 142-159.

Urban, B. (2012a). A metacognitive approach to explaining entrepreneurial intentions. Management Dynamics, $21(2), 16-33$.

Urban, B. (2012b). Applying a metacognitive perspective to entrepreneurship: empirical evidence on the influence of metacognitive dimensions on entrepreneurial intentions. Journal of Enterprising Culture, 20(02), 203-225.

Van der Merwe, M. (2002). A study of discrimination against women entrepreneurs when applying for financial assistance (Master's dissertation). University of Pretoria, Pretoria.

Wang, C. K., \& Wong, P.-K. (2004). Entrepreneurial interest of university students in Singapore. Technovation, 24(2), 163-172. 
Wennekers, S., Van Stel, A., Thurik, R., \& Reynolds, P. (2005). Nascent entrepreneurship and the level of economic development. Small Business Economics, 24(3), 293-309.

West, G.P., Bamford, C.E., \& Marsden, J.W. (2008). Constraining entrepreneurial economic development in emerging Latin American economies: Application and extensions of resource based theory. Entrepreneurship Theory and Practice, 32, 15-36.

Williams, C. C. (2009). The motives of off-the-books entrepreneurs: necessity-or opportunity-driven? International Entrepreneurship and Management Journal, 5(2), 203-217.

Zoogah, D. B., Zoogah, R. B., \& Dalaba-Roohi, F. (2015). Riding the tide: Management in Africa and the role of high-impact research. Africa Journal of Management, 1(1), 27-53. 